26. Surie S, Van der Plas MN, Marcus JT, Kind T, Kloek JJ, Vonk-Noordegraaf A, et al. Effect of pulmonary endarterectomy for chronic thromboembolic pulmonary hypertension on stroke volume response to exercise. Am J Cardiol. 2014; 114:136-40.

27. McCabe C, Deboeck G, Harvey I, Ross RM, Gopalan D, Screaton N, et al. Inefficient exercise gas exchange identifies pulmonary hypertension in chronic thromboembolic obstruction following pulmonary embolism. Thromb Res. 2013;132:659-65.

28. Zhai Z, Murphy K, Tighe H, Wang C, Wilkins MR, Gibbs JS, et al. Differences in ventilatory inefficiency between pulmonary arterial hypertension and chronic thromboembolic pulmonary hypertension. Chest. 2011;140:1284-91.

29. Melot C, Naeije R. Pulmonary vascular diseases. Compr Physiol. 2011;1: 593-619.

30. Velez-Roa S, Ciarka A, Najem B, Vachiery JL, Naeije R, van de Borne P, Increased sympathetic nerve activity in pulmonary artery hypertension. Circulation. 2004;110:1308-12.

31. Wasserman K, Whipp BJ, Koyal SN, Cleary MG. Effect of carotid body resection on ventilatory and acid-base control during exercise. J Appl Physiol. 1975;39:354-8.
32. Van der Plas MN, Surie S, Reesink HJ, van Steenwijk RP, Kloek JJ, Bresser P. Longitudinal follow-up of six-minute walk distance after pulmonary endarterectomy. Ann Thorac Surg. 2011;91:1094-9.

33. Kapitan KS, Clausen JL, Moser KM. Gas exchange in chronic thromboembolism after pulmonary thromboendarterectomy. Chest. 1990;98:14-9.

34. Mayer E, Jenkins D, Lindner J, D'Armini A, Kloek J, Meyns B, et al. Surgica management and outcome of patients with chronic thromboembolic pulmonary hypertension: results from an international prospective registry. J Thorac Cardiovasc Surg. 2011;141:702-10.

35. Jenkins DP, Biederman A, D’Armini AM, Dartevelle PG, Gan HL, Klepetko W, et al. Operability assessment in CTEPH: Lessons from the CHEST-1 study J Thorac Cardiovasc Surg. April 12, 2016 [Epub ahead of print].

Key Words: chronic thromboembolic pulmonary hypertension, pulmonary endarterectomy, cardiopulmonary exercise test, right heart catheterization, pulmonary hypertension

\title{
EDITORIAL COMMENTARY
}

\section{Understanding pathophysiologic changes occurring in chronic thromboembolic disease}

\author{
Robert B. Cameron, MD
}

\footnotetext{
From the Division of Thoracic Surgery, Department of Surgery, David Geffen School of Medicine at UCLA; and the Division of Thoracic Surgery, Department of Surgery and Perioperative Care, West Los Angeles VA Medical Center, Los Angeles, Calif.

Disclosures: Author has nothing to disclose with regard to commercial support.

Received for publication June 20, 2016; accepted for publication June 21, 2016.

Address for reprints: Robert B. Cameron, MD, Division of Thoracic Surgery, Department of Surgery, David Geffen School of Medicine, 10780 Santa Monica Blvd, Suite 100, Los Angeles, CA 90025 (E-mail: rcameron@ stanfordalumni.org).

J Thorac Cardiovasc Surg 2016;152:771-2

0022-5223/\$36.00

Copyright (C 2016 by The American Association for Thoracic Surgery

http://dx.doi.org/10.1016/j.jtcvs.2016.06.031
}

The pathophysiologic processes involved in the development of chronic pulmonary thromboembolic disease (CTED) from acute pulmonary embolism are poorly understood. ${ }^{1,2}$ In the most simplistic physiologic terms, one or more pulmonary emboli fail to resolve through fibrinolysis, leading to chronic obstruction of the pulmonary vascular bed and resulting in increasing right heart failure. There is substantial evidence, however, that the process may not be quite so simple. First, if simple obstruction were the only issue, pulmonary endarterectomy (PEA) should reliably lead to improvement or resolution of pulmonary hypertension in all cases-in fact, however, this does not occur. Some patients have persistent or residual pulmonary hypertension after PEA, and these patients face higher perioperative mortality as well as worse quality of life after

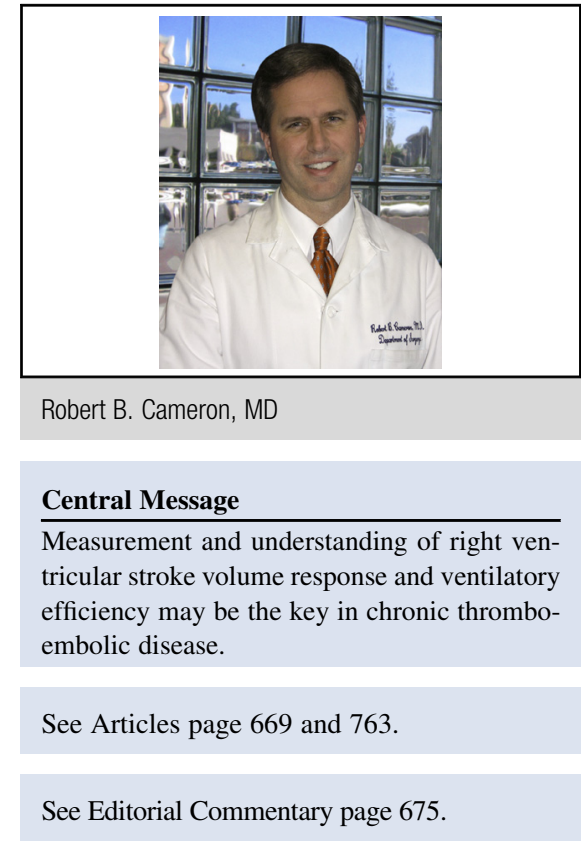

surgery. ${ }^{2,3}$ Jamieson and colleagues ${ }^{4}$ noted from their very large experience that patients with postoperative pulmonary vascular resistance greater than 500 dyne $\cdot \mathrm{s}^{-1} \cdot \mathrm{cm}^{-5}$ had a mortality as high as $30.6 \%$, primarily as a result of residual pulmonary hypertension. ${ }^{4}$ The only preoperative factor 
shown to a predict poor outcome was pulmonary vascular resistance greater than 1000 dyne $\cdot \mathrm{s}^{-1} \cdot \mathrm{cm}^{-5}$. If we have improved understanding of the pathophysiology, then better patient selection for PEA, development of better medical therapies to prevent progression to symptomatic disease, and earlier detection of the CTED that leads to chronic thromboembolic pulmonary hypertension all become possible.

In their study in this issue of the Journal, van Kan and colleagues ${ }^{5}$ cleverly opted to study an interesting group of patients: patients with symptomatic CTED but with normal pulmonary pressures at rest and exercise-induced pulmonary hypertension. Logically, this patient group, representing potentially early pathophysiologic CTED, could reveal more pathophysiologic information about mechanisms active during the development of chronic thromboembolic pulmonary hypertension than would be seen in patients with more end-stage disease. In fact, van Kan and colleagues ${ }^{5}$ found that there were distinct abnormalities during routine cardiopulmonary exercise testing of pulmonary vascular responses to exercise in patients with CTED. Specifically, a steep mean pulmonary arterial pressure to cardiac output slope was noted, indicating an abnormal right ventricular stroke volume response and a decreased pulmonary vascular compliance. The circulatory responses were also strongly correlated with an increase in dead space ventilation and decreased ventilatory efficiency during exercise. van Kan and colleagues ${ }^{5}$ went on to note that reversal of these findings on cardiopulmonary exercise testing performed 1 year after PEA correlated with improvements in symptoms and in exercise tolerance.
With knowledge of these early pathophysiologic changes in patients with CTED, which could be detected during routine cardiopulmonary exercise testing obtained for exercise-induced dyspnea before the development of late pulmonary arterial hypertension, it may be possible to detect early chronic thromboembolic pulmonary hypertension and therapeutically intervene before the development of advanced disease. From their data, van Kan and colleagues ${ }^{5}$ also suggest that if this is done, surgical mortality may decrease to very low levels simply from early surgical intervention. Limitations of this study, of course, lie in its retrospective design and its small patient numbers. Although definitive conclusions cannot be drawn, these data improve our understanding of CTED and motivate all surgeons to promote prospective trials evaluating these findings and early intervention in a disease that is notoriously difficult to understand and treat.

\section{References}

1. Poch DS, Auger WR. Chronic thromboembolic pulmonary hypertension: detection, medical and surgical treatment approach, and current outcomes. Heart Fail Rev. 2016;21:309-22.

2. Matthews DT, Hemnes AR. Current concepts in the pathogenesis of chronic thromboembolic pulmonary hypertension. Pulm Circ. 2016;6:145-54.

3. Mathai SC, Ghofrani HA, Mayer E, Pepke-Zaba J, Nikkho S, Simonneau G. Quality of life in patients with chronic thromboembolic pulmonary hypertension. Eur Respir J. April 13, 2016 [Epub ahead of print].

4. Jamieson SW, Kapelanski DP, Sakakibara N, Manecke GR, Thistlethwaite PA, Kerr KM, et al. Pulmonary endarterectomy: experience and lessons learned in 1500 cases. Ann Thorac Surg. 2003;76:1457-62; discussion 1462-4.

5. van Kan C, van der Plas MN, Reesink HJ, van Steenwijk RP, Kloek JJ, Tepaske R, et al. Hemodynamic and ventilatory responses during exercise in chronic thromboembolic disease. J Thorac Cardiovasc Surg. 2016;152:763-71. 